\title{
Concepts of structural underspecification in Bantu and Romance
}

\author{
Lutz Marten, Ruth Kempson, Miriam Bouzouita
}

Lutz Marten

School of Oriental and African Studies

Africa Department

Thornhaugh Street

Russell Square

London, WC1H 0XG

United Kingdom

email: lm5@soas.ac.uk
Ruth Kempson

\& Miriam Bouzouita

King's College London

Philosophy Department

The Strand

London, WC2R 2LS

United Kingdom

email: ruth.kempson@kcl.ac.uk, miriam.bouzouita@kcl.ac.uk 


\begin{abstract}
The paper explores parallelisms between Bantu (specifically Otjiherero) and Romance (through Latin and Spanish) with respect to left and right peripheries, and subject and object clitics. The analysis is formulated in Dynamic Syntax (DS, Cann et al. 2005) and centrally involves notions of structural underspecification. Through providing detailed analyses of different word order possibilities in the Bantu and Romance languages discussed, we show how DS concepts of structural growth over initially underspecified tree relations, such as the building of linked structures and unfixed nodes, provide a uniform basis for analysis for word order variation across the two language groups. We then extend our analysis to include Bantu subject/ object markers, which we analyse by employing the same formal tools as used in the analysis of Romance (object) clitics, namely unfixed nodes which have to be construed within a tightly locally restricted domain. Empirical support for our analysis comes from restrictions on the presence of object markers in passive and locative inversion constructions in Otjiherero, which we show to follow from independent constraints of the availability of unfixed nodes within a given domain. The analyses of Bantu and Romance presented show that despite differences in surface morphology between the two language groups, both exhibit a striking parallel with respect to the way lexical information and general structure building principles of DS interact. The difference between Romance clitic systems and the agglutinative morphology of Bantu subject and object makers is thus seen to be comparatively superficial, while the DS analysis brings out the strong structural parallelism between the two language groups. ${ }^{1}$
\end{abstract}

\title{
1 Introduction
}

In this chapter, we present an explanation of structural parallels between Bantu and Romance from the perspective of Dynamic Syntax, a grammar formalism which argues that natural language syntax can be explained as humans' ability to build structured representations of meaning from words in context, on a left-to-right basis. The model thus purports to reflect both natural language structures in relation to the linear order of words, and the way information progressively emerges during the incremental parsing of those words. Given this perspective, left and right periphery constructions are of specific interest, and we begin by illustrating similarities of periphery constructions in Romance and Bantu. In Section 2, we introduce the DS analysis of the left and right periphery in more detail, with reference to Spanish and Latin, based on previous DS analyses. Section 3 shows how the DS analysis of Romance can be extended to left and right periphery constructions in Bantu, which we illustrate from Otjiherero, Nsenga, siSwati, Swahili and Tumbuka and demonstrates how the DS model provides a straightforward analysis of these constructions, without stipulation of constructionspecific principles, which extends equally to Romance and Bantu. In the following Section 4, we probe the parallelism between Romance and Bantu, and the formal space in which this is expressed in the DS model further. We develop an analysis of Bantu subject agreement markers along the lines of Romance (object) clitics, which in our analysis reflect the more liberal word-order of Latin, and in particular local scrambling. 
Employing formal DS concepts, we construct an analysis of Bantu subject (and object) markers, which allows them freedom of construal within a very tightly locally restricted domain - what we call local underspecification. This analysis contradicts the view of Bantu verbal structure as morphologically fixed, but has the advantage of offering a principled analysis of subject and object-marking restrictions in passive and locative inversion constructions, which we illustrate from Otjiherero (Section 5). Our argument thus starts from the more familiar left and right periphery analyses of Romance, and proceeds to show how they are matched in Bantu. In a second step, we focus on a less obvious parallel, namely the type of process induced by Bantu (subject) agreement markers and Romance clitics (those that are syncretic in form), and show that this parallel can be brought out through the DS formalization of local underspecification, with the shared restrictions of locative inversion and passive as evidence.

\subsection{Romance-Bantu similarities on the left and right periph- ery}

It has often been proposed that Bantu and Romance share many structural characteristics despite differences in morphology. For example, objects can be fronted, with agreement and clitic doubling: ${ }^{2}$

$$
\text { Alenje njûchi zi-ná-wá-lum-a [Chichewa] }
$$

2.hunters 10.bees SM10-PAST-OM2-bite-FV

'The hunters, bees bit them.'

$$
\begin{array}{llll}
\text { El coche, María lo compró } & \text { [Spanish] } \\
\text { the car Maria CL } & \text { bought.3SG } & \\
\text { 'The car, Maria bought it.' } &
\end{array}
$$

Subjects can be postposed, with either a focus or backgrounding effect, or when postposed to the right of the full verb phrase, characteristically associated with contrast:

$$
\text { Zi-ná-wá-lum-a alenje njûchi [Chichewa] }
$$

SM10-PAST-OM2-bite-FV 2.hunters 10.bees

'They bit the hunters, the bees.'

$$
\begin{aligned}
& \text { Canta muy bien María [Spanish] } \\
& \text { sing.3SG very well, Maria } \\
& \text { 'She sings very well, Maria.' }
\end{aligned}
$$

There are also object-subject inversion effects in both language families, associated with contrastive interpretation:

$$
\begin{array}{lll}
\text { Alenje } \quad z i-n a ́-w a ́-l u m-a & \text { njûchi } & \text { [Chichewa] } \\
\text { 2.hunters SM10-PAST-OM2-bite-FV } & \text { 10.bees } & \\
\text { 'The hunters, they bit them, the bees.' } &
\end{array}
$$




$\begin{array}{llll}\text { Un coche compró } & \text { María [Spanish] } \\ \text { a car bought.3SG } & \text { Maria } & \\ \text { 'A car, Maria bought.' }\end{array}$

In all these cases there is variation. For example fronted objects require doubling in most Bantu languages, while in Spanish, clitic doubling is obligatory only if the subject intervenes between the object and the verb. However, despite variation both within and across the language families, the overall parallel between Bantu and Romance is clear. Object agreement markers on the verb, whether an identifiably separate clitic or an affix, result in increased word-order freedom; subjects and objects broadly differ in the referentiality implications associated with co-occurrence of the full NP with the agreement marker; and the subject, if right-peripherally placed may be placed either externally to the VP or, in some languages, immediately following the verb:

$\begin{array}{llll}Z i \text {-ná-wá-lum-a } & \text { njûchi } & \text { alenje } & \text { [Chichewa] } \\ \text { SM10-PAST-OM2-bite-FV } & \text { 10.bees } & \text { 2.hunters } & \end{array}$

'They bit them, the bees, the hunters.'

Compró María un coche [Spanish]
bought.3SG Maria a car
'She bought, Maria, a car.'

In both language families there is variation as to the extent to which "agreement" for non-subject expressions patterns alongside subject marking or more like a regular anaphoric process, hence giving rise to referentiality effects. In Spanish, for example, the dative construction behaves more like an agreement phenomenon than an anaphoric linkage between clitic and full NP that it doubles; and in Bantu, languages vary as to whether object marking, unlike subject marking, is subject to a referentiality restriction, or is an invariant agreement-like device.

Such left and right periphery effects in Romance have been the subject of considerable research, both in orthodox frameworks where the work is well known (Rizzi 1997 and others following; Monachesi 2005 in HPSG) and in the emergent Dynamic Syntax framework (DS; Cann et al. 2005, Kempson et al. 2006, 2007); and some work has been done extending these claims to the Bantu case (see Cocchi 2001 for a minimalist analysis, Cann et al. 2005, Marten 2007, Marten and Kempson 2002 for DS analyses). Certainly, the parallelism between the two language families even down to the level of individual-language variation suggests the phenomena should emerge as the consequence of interaction of general principles. The relevance of the DS perspective in this connection is the claim that syntax is no more than the progressive construction of semantic representation. In particular, the concept of building "unfixed" nodes as part of the ongoing construction process which is the heart of the DS claim, defines a family of relatively weak relations; and these provide the basis for an integrated characterisation of left and right periphery effects on a broad cross-linguistic basis (Kempson et al. 2007). There is in particular: (i) the construction of a highly restricted structurally underspecified relation where a node is introduced as unfixed but necessitates update within an individual predicate-argument array, the basis for 
local scrambling; (ii) the construction of an unfixed node requiring update within an individual tree, the basis for long-distance dependency and long-distance scrambling; and (iii) the building of paired ("linked") trees whose relation to each other is not that of mother/daughter at all but merely a relation of anaphoric connectedness. These three forms of structural underspecification are put together with the fact that pronouns themselves only provide a partial specification of node decorations, and so can be used as a basis for unifying any weak structural relation to provide the necessary update that will fix any such initially "unfixed" node. The result is an account of a range of intermediate effects such as clitic and pronoun doubling. With just the additional and independently motivated assumption that pronoun decorations may vary as to whether they allow further structural development of the node they decorate (the DS account of expletives: Cann et al. 2005), a further range of intermediate effects is obtained, in particular associated with expletives, and with doubling as displayed by Spanish datives. The overall result is that interactions between general processes of anaphora construal and the construction and update of structural relations provide a principled explanation of what are otherwise taken to be topic and focus effects, while nevertheless providing an analysis which is sufficiently fine-grained to provide a basis for the full range of cross-linguistic effects. Indeed Kempson et al. $(2006,2007)$ argue that the various topic and focus effects should be seen as grounded in such interactions rather than requiring these notions as syntactic primitives. The account thus makes a bid to be explanatory in a way that an account in terms of stipulating as many discrete formal structures (such as features, categories, or functional projections) as there are distinct patternings as in many current alternative analyses fails to match (e.g. Rizzi 1997, Cardinaletti 2007, Rivero forthcoming).

However, there are idiosyncracies associated with the interaction of object marking and local clause-internal variation in Bantu that are not displayed in Romance which threaten this claim, suggesting that the commitment to a single set of universally available principles for inducing the relevant data may not be sustainable. First of all, in the majority of Bantu languages, there can only be one object marker, whether direct or indirect object marking:

$\begin{array}{lll}\text { Ngi-m-nik-e } & k u d l a & \text { [siSwati] } \\ \text { SM1SG-OM1-give-PAST } & 15 . f o o d & \end{array}$

'I gave him/her food.'

$\begin{array}{ll}\text { Ngi-ku-nik-e } & \text { Jabulani } \\ \text { SM1SG-OM15-give-PAST } & \text { 1.Jabulani }\end{array}$

'I gave it to Jabulani.'

(11) *Ngi-ku-m-nik-e

$$
\text { *Ngi-m-ku-nik-e }
$$

Secondly, in the majority of Bantu languages where only one object clitic is allowed, passives preclude the presence of object markers, even when the verb is di-transitive, an equally puzzling restriction (although see Woolford 1995 for exceptions): 
òmbàpírà y-á-tjàng-ér-w-á òvá-nátjè (i Kàténáà)

9.letter SM9-PAST-write-APPL-PASS-FV 2-children (by Katenaa)

'A letter was written to the children (by Katenaa).'

*òmbàpírà $\quad y$-é-và-tjàng-ér-w-á

9.letter SM9-PAST-OM2-write-APPL-PASS-FV

Intended: 'The letter was written to them.'

Thirdly, as is known from Bresnan and Kanerva (1989) and others, locatives undergo inversion, and in so doing, induce "subject" agreement on the verb, suggesting that the concept of subject in Bantu is exceptional in that canonical subject and the locative share a potential to act as 'subject':

\section{m-òn-djúwó mw-á-hití é-rùngà \\ 18-9-house SM18-PAST-enter 5-thief}

'Into the house entered the thief.' (or, 'There was a thief entering the house.')

Finally there is the puzzle that unlike the canonical subject and like a passive subject, such pre-posed locatives cannot co-occur with object markers:

$\begin{array}{llll}{ }^{*} m \text {-on-djuwo } & m w-a & \text { ri } & \text { hiti } \\ \text { 18-9-house } & \text { SM18-PAST OM5 } & \text { enter } \\ \text { Intended: 'He/she entered the house' } & \end{array}$

This suggests that there may be cross-linguistically distinct bases for relations we informally understand as subject and object, so that the concepts of subject and object themselves continue to elude us even though they are so very familiar.

However, we shall argue to the contrary in this paper that the family of concepts of structural underspecification which are defined in DS as replacing concepts of movement equally apply to explain these apparent Bantu idiosyncracies, while retaining a universalist methodology on the syntactic processes themselves. In so doing, we shall provide an integrated analysis of Bantu passive and locative inversion that is not available in other frameworks. We will argue that the Bantu subject and object markers should be seen as associated with underspecified tree-relations that are restricted to requiring resolution within a local domain, an underspecification which until resolved, debars any other such underspecified tree relation. Moreover, as we shall show, this turns out to constitute a further parallelism with the Romance data. Kempson and Cann (2007) have argued that the family of patterns displayed by Romance clitics involves the construction of locally underspecified tree relations as a reflex of earlier Latin scrambling, an underspecification which is most clearly displayed by syncretic forms (e.g. Spanish me,te). The non-co-occurrence of such syncretic forms within an individual cluster is explained by the tree-logic restriction that only one token of a structurally underspecified relation is possible at any one time. ${ }^{3}$ What we shall argue is that exactly the same explanation carries over to the non-occurrence of more than one Bantu object clitic, and indeed to the restriction on both passive and locative inversion that object clitics are generally precluded. The consequence is that these arguments will provide strong and novel endorsement of the parallelism between Romance and Bantu, while at the same time providing an integrated account of what 
have been taken to be heterogeneous and puzzling Bantu data. Given that the concept of syntactic subject defined as a locally underspecified tree-relation will be new both within and beyond the DS framework (though see Wu 2005 for a related conclusion), we close by reflecting on what this tells us about the concept of subject in general.

However, before setting out our analysis, we provide a short introduction to DS in the following section, using a combination of Latin and Contemporary Castilian Spanish as the languages of illustration for the various concepts of paired "linked" trees, unfixed tree relations and consequent characterizations of such structures as Hanging Topic Left Dislocation, long-distance scrambling, pronoun doubling, shortdistance scrambling. We will also look at the account provided within DS of the morphological template behaviour of clitic clusters. ${ }^{4}$

\section{The Dynamics of Language Processing}

The methodology implicit in the Dynamic Syntax formalism is to take the constructs used in semantics and define them as tree-structure representations with a concomitant tree-growth process of establishing some interpretation in context. The central claim is that syntactic properties of natural language reside exclusively in the progressive growth of such tree-structure representations strictly following the dynamics of leftright processing: no additional level of syntax is needed. The type of tree-growth process we assume as the process of building up an interpretation for a string such as (17) involves a growth from just a single-node tree with a requirement to build-up a propositional structure, as in the left below in (18) through a sequence of transitions to yield some final tree, being the tree on the right in $(18):^{5}$

María compró
Maria bought.3sG a coche
'Maria bought a car.'

Parsing María compró un coche in (17)

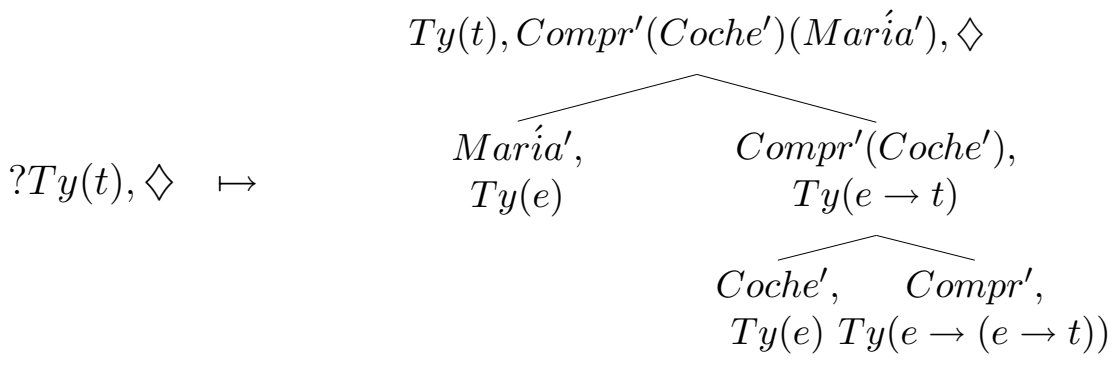

In example (18), diagrammatically displaying this process, a lot of implicit content is packed into $\mapsto$, which symbolises the concept of tree growth. Central to the concept of tree-growth is the concept of requirement: ?X for any decoration $\mathrm{X}$. Decorations on nodes such as ?Ty $(t)$, ?Ty $(e), ? T y(e \rightarrow t)$ etc. express requirements to construct formulae of the appropriate type on the nodes so decorated (propositions, terms and predicates respectively), and these drive the subsequent tree-construction process. ${ }^{6}$ 
The general dynamics is first to unfold a tree structure imposing such requirements following a mixture of top-down general tree-growth strategies and bottom-up lexical actions that contribute concepts and other aspects of structure, and then compositionally to combine those concepts in a strictly bottom-up fashion to yield the overall interpretation, in which all requirements must have been satisfied. For any language, the process of growth of structure is strictly monotonic, and for any one interpretation, hence wellformedness, there must be at least one sequence of progressively enriched partial trees between input tree and resulting logical form in which all requirements are met.

The formal system underpinning the partial trees that are constructed is a logic of finite trees (LOFT: Blackburn and Meyer-Viol 1994). There are two basic modalities, $\langle\downarrow\rangle$ and $\langle\uparrow\rangle$, such that $\langle\downarrow\rangle \alpha$ holds at a node if $\alpha$ holds at its daughter, and the inverse, $\langle\uparrow\rangle \alpha$, holds at a node if $\alpha$ holds at its mother. Functor and argument relations are distinguished by defining two types of daughter relation, $\left\langle\downarrow_{0}\right\rangle$ for argument daughters, $\left\langle\downarrow_{1}\right\rangle$ for functor daughters (with their inverses $\left.\left\langle\uparrow_{0}\right\rangle,\left\langle\uparrow_{1}\right\rangle\right)$. There is also an additional link operator, $\langle L\rangle$, which relates paired trees, with a link relation from a node in one tree to the top node of another. This tree language plays a critical role in defining the individual steps of tree growth; and procedures are defined for step-wise building up of such structures either by computational actions or by lexical or even pragmatic actions. All are defined in the same vocabulary, a set of context-relative actions for updating representations of interpretation. Such formal tree languages by definition provide characterisations of such structural relations as dominate; and in LOFT, the concept of dominate is defined in the following terms: a node can be described as dominated by a node $\operatorname{Tn}(a)$ when $\left\langle\uparrow_{*}\right\rangle T n(a)$ holds at that node, that is when the node identified as $\operatorname{Tn}(a)$ is along some sequence of mother relations from the present node.

Such structural relations will play an important part in what follows, but we start with the characterisation of how predicates are built from lexical specifications.

\subsection{Lexical information provided by verbs}

As in other frameworks, verbs are the major projector of structure, for which actions are defined that induce some or even all of the propositional template they express.

Result of running lexical actions of compró

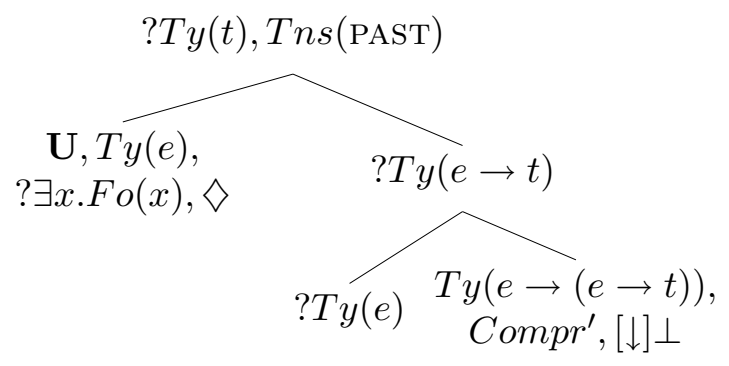

In Spanish, a subject pro-drop language, verbs project full propositional structure, in which (i) a subject argument node is decorated with a placeholder i.e. a metavariable of the form $\mathbf{U}, \mathbf{V}, \ldots$ of type $e$, that stands for some value to be assigned either 
from context or from the construction process, and (ii) an object node which requires subsequent development, as expressed by the requirement ?Ty(e) in (19).

Taking first the subject node decoration, these meta-variables all have an associated requirement, ? $\exists x . F o(x)$ which guarantees they must be updated. The pointer is positioned at this node, since this allows the subject to be identified contextually as the very next step. Strings made up of either a SVO sequence or a VSO sequence are thus taken to be unmarked (we shall see in the next section how left-peripheral expressions may be treated as decorating distinct nodes, external to the propositional structure itself and identified solely through replacement of the meta-variable). ${ }^{7}$

The effect is that verbs induce a sequence of actions which might equivalently be expressed by a pairing of verb plus subject pronoun. The decoration of argument nodes with a meta-variable, for example, is the intrinsic property of pronouns, underspecification with respect to content being their hallmark. Whether provided by parsing a pronoun or a pro-drop verb, all such place-holding devices must be supplied with an assigned value (notice the requirement for a full formula ? $\exists x . F o(x)$ ); and different types of anaphoric expression can be defined according to the different constraints on that process which they impose. Values for reflexive pronouns have to be updated within a given single predicate-argument structure, values for other pronouns outside such locally defined structure. Meta-variables projected as part of the intrinsic specification of the verb, on the other hand, lack any such restriction, and can have their value identified either locally or nonlocally, indexically, or from some term provided later on in the construction process, where the choice of value involves general cognitive constraints such as relevance (Sperber and Wilson 1995). The object node, on the other hand, the other node induced by the verb's actions in (19), has only a requirement that the node be developed so further linguistic input is essential (with no provided meta-variable, there is no license to use context-provided values).

In virtue of the grounding in LOFT, trees are not however taken as syntactic primitives as in other frameworks, but are built up by explicit tree-growth procedures, defined as actions which induce the structure in (19), and then feed into whatever structural or pragmatic operations are suitably triggered. The so-called "bottom-node restriction", $[\downarrow] \perp$, which is part of the decoration of the predicate node in (19) is definitive of regular lexical specifications that the node to which the formula decoration is provided constitute a terminal node in the resulting tree, closing off development of the node so decorated, so that no further expansion is possible. As we shall see, this restriction may get lost in some words.

\subsection{Context-dependence and lexical specifications for pronouns}

The process of providing such a meta-variable with a value is a substitution process, its replacement having to be selected from the set of terms made available during the construction process, characteristically from the context. For example, in (20), lo is naturally understood as picking out the same individual as picked out by the antecedent use of Pablo:

$$
\begin{array}{lllllll}
\text { ¿Quién } & \text { ama } & \text { a } & \text { Pablo? } & \text { María lo } & \text { ama } \\
\text { who } & \text { love.3SG } & \text { A } & \text { Pablo } & \text { Maria } & \text { CL } & \text { love.3SG }
\end{array}
$$


'Who loves Pablo? Maria loves him.'

The concept of the context-dependence of anaphoric expressions in language is familiar enough. What is less orthodox is the assumption that it is to be defined as a tree-update process; and with contexts also represented as (partial) trees, anaphora resolution can apply equally to the update of a pronoun from antecedent terms within the structure under construction:

Pablo cree que María lo ama
Pablo think.3SG that Maria CL love.3SG
'Pablo thinks that Maria loves him.'

For the identification of $l o$ in (21), the context relative to which that interpretation process takes place includes the partial structure containing the subject node with its decorations. So there is no distinction between grammar-internal and discourse uses of pronouns: both are analysed alike as a tree update process in which the meta-variable gets to be provided with a term as value by substitution. In canonical uses of pronouns, like all other content words, the pronoun has "the bottom restriction" that whatever value it is assigned must be taken as decorating a terminal node in the tree.

However, by adopting a representationalist stance, with pronoun construal seen as a substitution process, we can integrate anaphoric and apparently non-anaphoric uses of pronouns into a single form of explanation. In Spanish, as already briefly discussed above, there is widespread clitic doubling of dative expressions that occur either preor post-verbally (e.g. the pre-verbal dative NP is doubled by les in (22)), sometimes referred to as an agreement phenomenon (Franco 2000 inter alia):

$$
\begin{aligned}
& \text { A familias de pocos medios les ofrecieron } \\
& \text { to families of small means CL offered.3PL cheese } \\
& \text { 'To low-income families, they offered cheese.' }
\end{aligned}
$$

From a DS perspective, such clitic uses can be seen as anaphoric devices of just the same sort as more regular pronouns, with just a minor loosening of the defining properties of what it is to correspond to a regular lexical item of the language: they have lost this bottom restriction, with the result that the meta-variable they provide, in (23) represented as $\mathbf{U}$, can be updated by STRUCTURE as part of the construction process. ${ }^{8}$ As a result, these dative clitics have broader distribution, allowing identification either from context or from the construction process, retaining their anaphoric properties but in a modified form. 


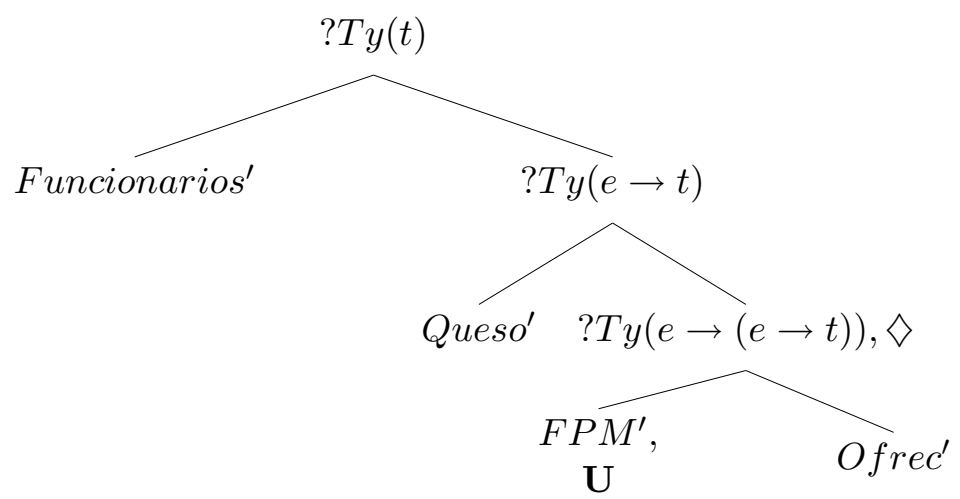

The effect, however, is that doubling in such cases will not impose a referentiality constraint, as the meta-variable provided by the clitic can be given a value by any term whatever of appropriate type, even allowing indubitably quantified NPs to be doubled:

$$
\begin{array}{lllllll}
\text { A nadie } & \text { le } & \text { devolvió } & \text { María } & \text { su } & \text { manuscrito } \\
\text { to nobody } & \mathrm{CL} & \text { returned.3SG } & \text { Maria } & \text { his/her } & \text { manuscript }
\end{array}
$$

'Maria didn't return anyone their manuscript.'

This renders them equivalent to the decorations provided by the verb for its subject in subject pro-drop languages, hence their supposed agreement-displaying properties.

\subsection{The dynamics of long-distance dependency}

This dynamics of initially constructing some incomplete specification with subsequent provision of its update applies also to the projection of structure. The core claim of DS is that ALL syntactic mechanisms can be seen in terms of tree growth and update, and in particular, discontinuity phenomena are modelled by defining structural concepts of underspecification and update as a direct analogue of the formula underspecification and update, taken to be the underpinning of anaphora resolution. In (26), for example the expression un coche is construed as providing a term for the resulting logical form, but the node which it decorates does not yet have its relation to the root, $\operatorname{Tn}(0)$, fixed within the overall structure (indicated by the dashed line): ${ }^{9}$

UN COCHE compró

a car bought.3SG

'A CAR, he/she bought.'

(26) Parsing Un COCHE in (25)

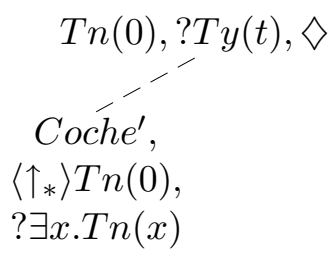


Once this unfixed node is decorated, the actions of the verb can be used to project a full template of propositional structure; and, with the subject having been contextually identified, say as someone called Maria, the pointer returns to the object node for further development. This move provides the necessary input for fixing the unfixed node, with this delayed update also solving the subcategorisation requirement of the two-place predicate projected by the verb:

\section{Parsing UN COCHE compró in (25)}

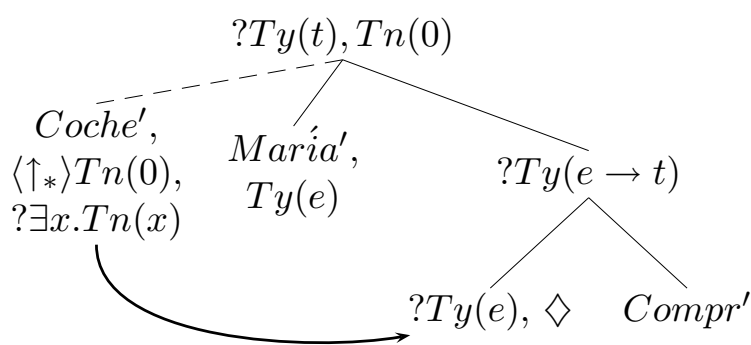

And, given that the only restriction on this unification process is that the result be an update, we expect that it can also apply in the presence of a pronoun decorating the object node, as long as that pronoun has no bottom restriction. So we predict the availability of long-distance dependency effects in Spanish with a preposed dative expression and dative doubling, as in (22), the so-called Clitic Left Dislocation (CLLD) phenomenon.

Like the process of anaphora resolution, the process of constructing an unfixed node is in principle available at any point, allowing the construction of an unfixed node at some relatively late point in the parse. There is an asymmetry between early and late application of such construction processes, however, in virtue of the tree either being radically underspecified (early in a parse) or all but complete (late on in the parse process). In particular, DS assumptions lead us to expect a more restrictive result once some emergent tree is complete apart from completing the formula decorations on its nodes. General restrictions on tree development dictate that once the pointer is at a node with some imposed requirement(s), it cannot move up from that node except as particular licence is defined to enable it do so. One such case is in the parsing of pronouns. In parsing pronouns, although the formula value may remain to be provided at some late stage, a type value Is established, and so the construction process can proceed. However, the delay in completing the decorations on the node which this gives rise to has to be essentially local, as a strict bottom-up compositionality requirement on the containing predicate-argument structure must nevertheless be satisfied. In consequence, though the pointer can move away from a type-decorated node as long as it has some interim place-holder decoration, it will have to return to the partially decorated node so that a fixed value for that node is provided when the semantic information on the tree is compiled. This late construction of a subtree can be achieved by a process of building an unfixed node of a type that matches the node from which it is built, decorating it suitably, and then unifying the two (so-called Late*Adjunction). This sequence of steps will for example apply in deriving a construal for (28). 
Les ofrecieron queso a familias de pocos medios

CL offered.3PL cheese to families of small means

'They offered cheese to low-income families.'

With the clitic pronoun decorating a third argument node of ofrecieron early on in the parse, Late*Adjunction can induce a node of type $e(T y(e))$ for the parse of $a$ familias de pocos medios which, once established, unifies with that node. The result of this introduction and decoration of an unfixed node at this point in the derivation yields as a consequence the very strict locality restriction at the right periphery (sometimes called 'The Right Roof Constraint'), which, although well known, has never been satisfactorily explained. As a bonus, this account provides a basis for analysing the inversion phenomenon characteristic of the Romance languages:

$$
\begin{array}{lll}
\text { UN COCHE, compró } & \text { María } \\
\text { a car bought.3SG } & \text { Maria } \\
\text { 'A CAR, Maria bought.' } &
\end{array}
$$

Early on in the derivation, an unfixed node is introduced, decorated by the parse of un coche. This weak tree relation is not updated immediately but only after the verb has been processed, hence with a delay in its construal. The projection of content for the subject node is also delayed, this node only being introduced as part of the information provided by the verb, with its content provided once a predicate has been compiled from verb and object in combination. Once the pointer has returned to the subject node, Late*Adjunction can then be used to provide an intervening node for parsing the end-placed subject expression and so establishing the construal of that subject.

(30) Parsing Un COCHE compró María in (29)

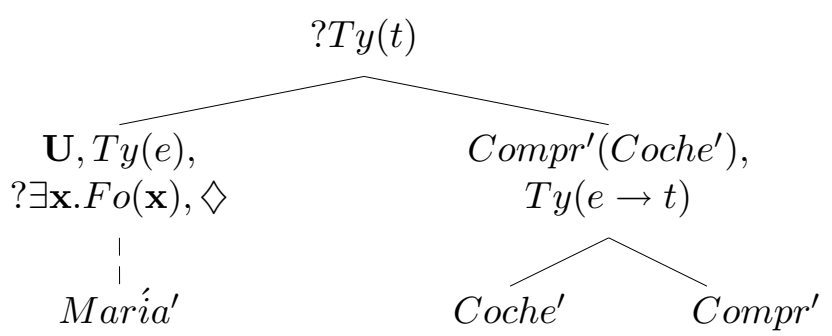

This finally leads to a tree no different from that which could have been derived by parsing (17) (see the the right-hand side tree in (18)). As mentioned above, wellformedness in DS is not defined by the final tree of a derivation, but rather by the monotonic transition from an initial to some final tree.

There is however an important constraint, which is an immediate consequence of the concept of partial trees. Just like any individual fixed node, any unfixed node, is nevertheless identified by its tree-node value - in these very weak cases solely by the dominate relation that defines it. But this means that there can effectively never be more than one unfixed node at a time, because any two such identified nodes cannot be distinguished, and so would lead to incompatible tree decorations. The derivation of (29) notably meets this constraint: at no point in the sequence of trees over which its interpretation is built up is there ever more than one unfixed node. 


\subsection{Constructing trees in tandem}

The one missing part of the DS jigsaw of interacting mechanisms is the details of how paired so-called "linked" trees are constructed. These are licensed by a mechanism which induces paired trees on the assumption that they must share a term which occurs in both. The two trees are, in effect, introduced in tandem, using LOFT modal requirements to ensure an anaphoric substitution process across the pair of trees. Relative clause construal provides a core example (see Kempson et al. 2001, Cann et al. 2005). But this very same device applies equally to provide a basis for Hanging Topic Left Dislocation (HTLD) structures (Anagnostopoulou et al. 1997), The leftperipheral expression is analysed as providing the trigger for introducing a tree linked to the rootnode which is to be of type $e$, which that expression duly decorates, with an additional restriction that the root node with requirement ?Ty $(t)$ must now be constrained to contain a copy of the term projected from the left-peripheral noun phrase so as to satisfy the sharing-of-terms requirement dictated by the LINK relation. This modal form of requirement determines the presence of a suitably construed pronoun in the twinned structure, which the facts of HTLD corroborate:

Este coche, Pablo lo compró

this car Pablo CL bought.3SG

'This car, Pablo bought it.'

* Este coche, Pablo compró

this car Pablo bought.3sG

'This car, Pablo bought.'

The only exception to this REQUIRED presence of a lexical pronoun is the case of subject pro-drop structures, i.e. just those cases where the verb projects its argument nodes decorated with a meta-variable, exactly as though a lexical form of pronoun had been present, since these can satisfy that same requirement by identifying the meta-variable appropriately.

The result is that a range of strategies is available in the opening stages of a parsing process, any one of which can apply; and this gives us a basis for explaining the blurring effect associated with the subject position in pro-drop languages, able to be construed either as a backgrounding device, or as a focussed term, or more neutrally, and the reported difficulty in some cases of differentiating what have been distinguished as HTLD and CLLD structures (de Cat 2007). In particular we expect both the availability of building an unfixed node, decorated, and presumed to be incorporated into the single emergent structure as it unfolds, and the building a pair of linked structures, with the second structure suitably construed as having an interpretation dictated by the decoration on the first, as shown below.

It is notable how if these are the only two options available for parsing pre-verbal subject expressions in Spanish, we derive the result observed in Zubizarreta (2001) that Spanish subjects are invariably in some sense external to the clause.

$$
\begin{aligned}
& \text { Martín lo escribió } \\
& \text { Martin CL wrote.3SG } \\
& \text { 'Martin wrote it.' }
\end{aligned}
$$


Parsing Martín (a) as decorating an unfixed node or (b) as a linked structure

(a)

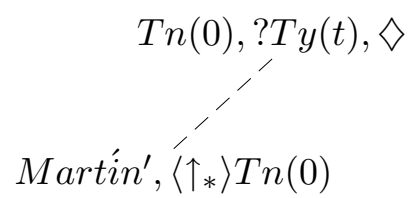

(b)

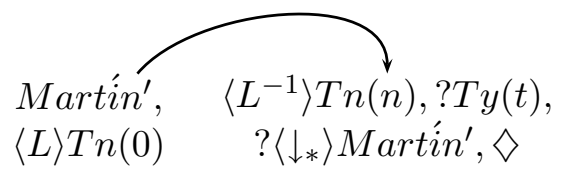

The two strategies of building linked structures or an unfixed node within an individual structure are in principle also available at the right periphery though to rather different effect. If an independent linked structure is constructed, it will be the value assigned to the meta-variable of the pronoun that is identified from context: the construal of the end-placed NP will then have to be fixed to be co-extensive with value of the meta-variable in order to match the linked-structure requirement of shared term in the paired structures. Hence the reported backgrounding effect that can be conveyed by so-called Pronoun Doubling. Alternatively, an unfixed node can be introduced by Late*Adjunction whose decoration provides a value for the meta-variable. This typically gives rise to contrastive or new information effects in virtue of that late construction (see Kempson and Cann 2007). This predicted flexibility at both left and right peripheries is a bonus of the parsing perspective, since unlike in more conventional grammar formalisms, there is no commitment to a single assignment of structure for an unambiguous string. To the contrary, this framework provides a range of tree-growth strategies, which may feed each other, giving rise to a mixed array of effects.

Taking a step back from the details, what is striking in the set of explanations which this account makes possible is how few stipulations there are: no single identifiable structure is defined by a mechanism individual to that structure. Instead we have general principles of tree development interacting with general principles for anaphora construal: it is these together that determine the range of effects associated with HTLD, CLLD, Pronoun Doubling, expletives and so on.

\subsection{Scrambling and locality constraints on structural under- specification}

Locality constraints on actions for tree-growth are not all merely an epiphenomenon of the stage in the construction process at which update must have taken place. In free word-order languages, in particular, there is evidence of local processes of tree construction in anticipation of the verb. To express this in a principled way, we push the parallelism with anaphora resolution yet further, and extend the articulation of different locality restrictions to structural processes of tree growth, articulating analogous restrictions on update of tree growth, defining a sub-type of structural underspecification which requires update within a single propositional domain (so-called Local*Adjunction). Local*Adjunction applies to a type-t-requiring node. It licenses the introduction of an argument node and an underspecified functor relation, in effect a restriction on update within a given local scope domain $\left(\left\langle\uparrow_{1}^{*}\right\rangle\right.$ denotes a sequence of relations, of which the daughter must involve a functor type-decoration): 


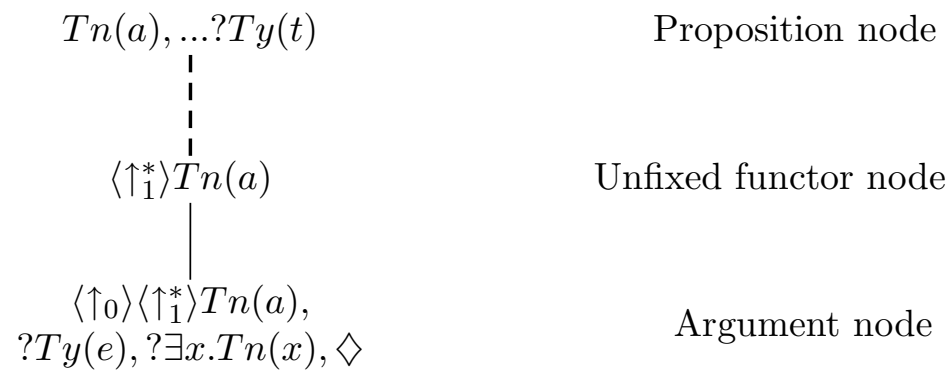

What the rule induces is one fixed argument daughter node immediately dominated by a node whose relation to the node of introduction is an underspecified relation across functor relations, $\left\langle\uparrow_{1}^{*}\right\rangle$ - in effect the functor spine along which argument nodes can be constructed (the unfixed tree-relation is diagrammatically indicated by a dashed line). The node introduced by these actions has a requirement for an argument term (of type $e$ ), a description of its tree relation to the point of departure, and a requirement for a fixed value. As we shall see, this rule is used to induce structure for local scrambling effects. To see the general application of this, we need to revert to Latin, the source language from which Romance languages developed, as this displays the relatively free word order variation symptomatic of free use of Local*Adjunction, applying in conjunction with constructive use of case. What the case specification ensures is immediate update of any such unfixed node, fixing the structural relation of the node decorated by the expression well before the occurrence of the verb, thereby allowing the rule to apply again to introduce a further unfixed node. So as in (36), we can license the building of structure from first servum and then Xerxes:

$$
\begin{array}{lll}
\text { Serv-um } & \text { Xerxes } & \text { cecidit } \\
\text { slave-ACC } & \text { Xerxes-NOM } & \text { killed.3SG }
\end{array}
$$

'Xerxes killed the slave.'

This sequence of words can be in any order. This is where the restriction imposed by the system that there be only one unfixed structural relation of a type at a time has a role to play, since any duplication of the process without any such update would lead to immediate collapse of the two unfixed tree relations, yielding just one argument node for some predicate simultaneously characterised as a subject and an object argument. The effect of case as a constructive mechanism for fixing any such underspecified tree relation is therefore essential to the effective re-use of Local*Adjunction as a strategy. ${ }^{10}$ Of course, once any one relation is fixed, (as in (37b) below), another unfixed node can be introduced, following through on the same sequence of actions; and the interim result (refcomplicatedd) is a partial tree with a set of argument nodes but as yet lacking any predicate node with which to combine. Notice in particular the pair of argument nodes (without having parsed a verb) in (37d), a pattern reflected by the later clitic clusters that emerged in the Romance languages. The verb then follows, filling out the remainder of the propositional structure to yield the appropriate output tree with Xerxes ${ }^{\prime}$ as subject argument $S e r v^{\prime}$ as object argument to the predicate Caed ${ }^{\prime}$. Unlike 
two case-distinguished unfixed nodes, either subject or object nodes induced by actions of the verb harmlessly collapse with those introduced as unfixed and updated through constructive use of case (Nordlinger 1998), as annotations provided by the verb are compatible with those provided by computational actions used in parsing the NPs - the formula decorations provided on the verb-induced argument nodes are metavariables, compatible with all formula updates. So the tree projected by the lexical actions of cecidit can be constructed by applying those actions to the tree $(37 \mathrm{~d})$. This allows 'free' word order effects without any necessary interpretational difference, with pragmatic constraints free to determine preferential orderings.

(a) Locally unfixed node

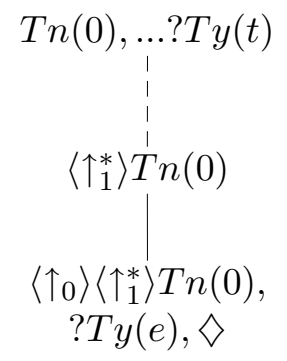

(c) Locally unfixed node

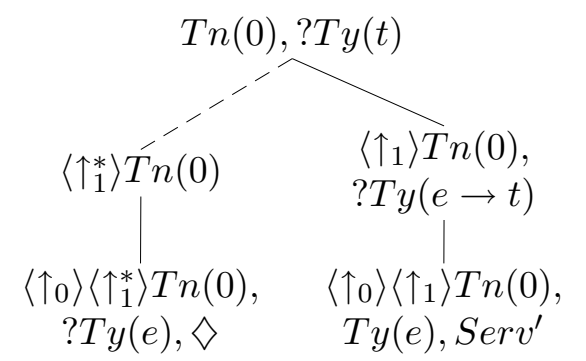

(b) Parsing Serv-um

$$
\begin{gathered}
\operatorname{Tn}(0), \ldots ? T y(t), \diamond \\
\left\langle\uparrow_{1}\right\rangle \operatorname{Tn}(0), \\
? T y(e \rightarrow t) \\
\left\langle\uparrow_{0}\right\rangle\left\langle\uparrow_{1}\right\rangle \operatorname{Tn}(0), \\
T y(e), \operatorname{Serv}{ }^{\prime}
\end{gathered}
$$

(d) Parsing Xerxes

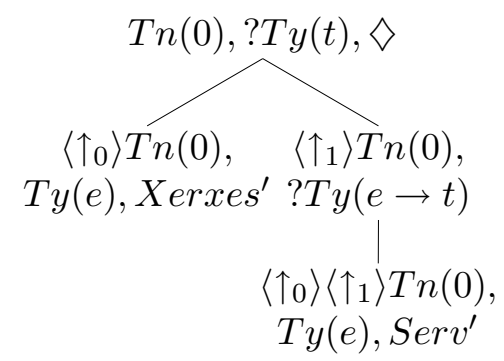

In the modern Romance languages, with case no longer being expressible in the morphology of the full NPs, the effects of the actions of Local*Adjunction are now restricted to its use with clitic pronouns. ${ }^{11}$ First, in finite clauses, they invariably occur in an early position, prior to the verb, exactly as the effects of multiple applications of Local*Adjunction plus case update (see Bouzouita 2007, in preparation, Bouzouita and Kempson 2006, and Kempson and Cann 2007 for a diachronic account of clitic placement). Furthermore, being stored as a lexical device, each is associated with a distinct scrambling mechanism. For example, the third person accusative clitics fix their structural relation to the dominating type-t-requiring node immediately. However, many of the clitics display syncretic properties, e.g. French me, te and Castilian Spanish le. These fail to identify whether the argument introduced is a direct or an indirect object and are assigned lexical actions that induce the construction of a locally unfixed node WITHOUT immediate update. The syncretic form thus matches the weakeness of the update they provide. It is these actions which the agreement forms of Bantu are redolent of; so we return to this type of update action in due course. The characteristic rigid pre-verbal positioning but allowing other clitics to intervene 
between the clitic and the verb echoes the multiple applications of Local*Adjunction plus update displayed in scrambling, a grouping which over time became calcified in the lexicon as a single look-up, hence eventually a single lexical entry. In some languages, e.g. Italian, these get written as one word, glielo; in other languages, e.g. Spanish, they may become associated with idiosyncratic and noncompositional forms of interpretation. ${ }^{12}$ (This effect is missing from the Bantu languages where the almost invariant case syncretism has not led to any such multiple clustering.) The composite effect achieved by the Dynamic Syntax analysis is a characterisation of clitic template phenomena as a lexicalisation of the earlier free word order system. The update actions which had licensed flexibility of NP ordering in the earlier Latin system, where they were freely available, are now lexically associated with individual clitics or clitic clusters. On this view, it is the retention of case specifications only in the lexicon with the clitic pronouns that ensured that the effects of Local*Adjunction are reflected in clitic placement. Furthermore, because these are now all individual lexical stipulations, each can only reflect one amongst the possible mechanisms that give rise to scrambling effects.

\section{$3 \quad$ Left and right periphery effects in Bantu}

The structural possibilities at the right and the left periphery available in Romance are mirrored by similar structures in Bantu, as already shown in Section 1. We can thus use the Romance analyses of the previous sections for developing analyses of similar structures in Bantu, and so in this section, we give a cross-Bantu survey to show how the range of variation encountered is similar to variation across Romance. For instance, the use of *Adjunction and LINK is exploited in Bantu as well, given the optional doubling phenomenon at least with object markers; and, like in Romance, these general mechanisms interact with the tree-update actions which the subject and object markers provide (see Marten 2007). Bantu subject and object markers are sometimes referred to as agreement markers, but are better analysed from the semantic perspective as quasi-independent pronominal elements (e.g. Bresnan and Mchombo 1987, Marten and Kempson 2002). They behave like pronouns in terms of their referential properties much as Romance clitics, and although they appear to be more morphologised in Bantu than in Romance in terms of positional restrictions, we will argue in the following section that, like the Romance clitics, they should be analysed by employing the concept of locally unfixed node, but with greater systematicity, hence demanding a more general form of explanation. At the left periphery, object-argument nodes can be introduced through *Adjunction without co-referring object marker in some languages, such as Tumbuka (38), although in many languages, the more common, or sometimes only strategy is to have an object marker (39):

$\begin{array}{lll}\text { Ngóoma } & \text { ti-zamu-limilír-a } & \text { namchéero [Tumbuka] } \\ \text { 9.maize } & \text { SM1pl-FUT-weed-FV tomorrow } \\ \text { 'Maize we will weed tomorrow.' (Downing 2006: } 62)\end{array}$




Q: Ba-ntfwana, ba-ba-nik-e-ni? [siSwati]
2-children SM2-OM2-give-PAST-what
'What did they give to the children?'
A: Tin-cwadzi, ba-ti-nike
10-books SM2-OM10-give-PAST $\quad$ 2-children
'Books, they gave (them) to the children.'

In the siSwati example, tin-cwadzi 'books' is projected onto a linked structure, as we will see shortly, siSwati object makers have not lost their bottom restriction indicative of the node having to be a terminal node in the resulting tree. At the right periphery, subject and object expressions are found, and the phenomenon of clitics losing their bottom restriction may seem to have extended further than in Romance since, in some languages, the doubling phenomenon is generalised to all object clitics, and even in some cases internally to the structure under construction (rather than between pairs of trees). First, there is the distribution that is widespread in Romance - in siSwati, object expressions tend to occur with object clitics only when they are right dislocated, as the adverb placement in (40) indicates. But in Swahili, object clitics can occur with co-referential objects internally to the verb-phrase sequence, indicating that in Swahili object clitics have lost the bottom restriction:

$\begin{array}{llll}N g \text {-a-yi-bon- } a & \text { kahle } & \text { inja } & \text { [siSwati] } \\ \text { SM1sg-PAST-OM10-see-FV } & \text { well } & 10 . \operatorname{dog} & \\ \text { 'I saw the dog well.' } & & \end{array}$

$$
\begin{array}{lllll}
* \text { Ng-a-yi-bon-a inja } & \text { kahle } & & \\
\text { Gidyoni } & a-l i-k u w a & h \text {-a-ja-mw-on- } a & \text { huyo } & k i \text {-jana } \\
\text { Gidyoni } & \text { SM1-PAST-be } & \text { NEG-SM1-PERF-OM1-See-FV } & \text { DEM1 } & \text { 7-youth } \\
\text { vizuri } & \text { [Swahili] } & & & \\
\text { well } & & & &
\end{array}
$$$$
\text { 'Gidyoni had not seen the youth well.' (Mvungi n.d.: 126) }
$$

However, in apparent marked contrast to the Romance pattern, many Bantu languages have a restriction on the number of object markers available in the verbal template. Thus languages like siSwati, Swahili and Otjiherero allow only one object marker per verb, although multiple object markers are found, for example, in Tswana, Rundi and Kinyarwanda. While the restriction on the number of object markers is often taken as morphological, we will argue below that it is in fact syntactic, in that object markers project locally unfixed nodes, from which the restriction to only one object marker at a time follows immediately. ${ }^{13}$ The analysis involving locally unfixed nodes predicts furthermore that there should be no significant restrictions on the case or thematic role of the object clitics, in contrast to Romance, where clitics are a reflection of an older case system, and this prediction is borne out:

$$
\begin{aligned}
& \text { ú-térék-èr-à òvá-éndà ònyàmà p-òngàndà [Otjiherero] } \\
& \text { SM1-cook-APPL-FV 2-guests 9.meat 16-9.house } \\
& \text { 'S/he cooks meat for the guests at home.' }
\end{aligned}
$$


ú-vé-térék-èr-à ònyámà p-òngàndà

SM1-OM2-cook-APPL-FV 9.meat 16-9.house

'S/he cooks them meat at home.'

$$
\text { ú-i-térék-èr-à òvá-éndà p-òngàndà }
$$

SM1-OM9-cook-APPL-FV 2-guests 16-9.house

'S/he cooks it for the guests at the house.'

$\begin{array}{lll}\text { ú-pé-térék-èr-à } & \text { òvá-éndà ònyàmà } \\ \text { SM1-OM16-cook-APPL-FV 2-guests } & 9 \text {.meat } \\ \text { 'S/he cooks meat for the guests there.' }\end{array}$

Although Otjiherero allows only one object marker per verb, object markers can mark the dative (44), direct (45) or locative (46) complement of the verb. Object markers are formally distinguished for different noun classes, but not for case. This is directly explicable on the assumption that the object markers themselves induce the unfixed node and provide it with a meta-variable decoration, without any structural update of that node relation taking place. In effect, the only structural information they provide is that they are an argument of the predicate corresponding to the verb. Subject expressions, too, as in the Romance languages, are found in post-verbal, inverted position and often carry presentational focus in virtue of this late placement, or alternatively, may be associated with an afterthought interpretation (48):

$$
\begin{aligned}
& \text { à-léndò à-fwík-à [Nsenga] } \\
& \text { 2-visitors SM2.PAST-arrive-FV }
\end{aligned}
$$

$$
\begin{array}{ll}
\grave{a}-f w i k \text { - } a & \text { a-léndò } \\
\text { SM2.PAST-arrive-FV } & \text { 2-visitors } \\
\text { 'Guests have arrived.' /'They have arrived, the guests.' }
\end{array}
$$

Nsenga subject markers have lost their bottom restriction, and so update both through *Adjunction and by constructing a linked node is possible, accounting for the two different readings. Again, we find variation across Bantu, as, for example, in Otjiherero, subject markers cannot be associated with update by Late*Adjunction (49), and post-verbal subjects with agreeing subject marker can only be introduced through a LINK structure yielding (50), with its associated co-referring afterthought interpretation. However, since the different update possibilities of Otjiherero clitics are specified lexically, we would expect variation within the language as well as crosslinguistic variation, and indeed, update within the propositional structure is possible with (grammaticalised) locative subject markers (51) indicating that they have lost their bottom restriction:

$$
\begin{aligned}
& ?^{*} v \text {-á-hití òvá-ndì [Otjiherero] } \\
& \text { SM2-PAST-enter 2-people } \\
& \text { v-á-hití, òvà-ndù } \\
& \text { SM2-PAST-enter 2-people } \\
& \text { 'They entered, the people.' }
\end{aligned}
$$


'There entered people.'

Bantu languages thus make use of the same strategies as the Romance languages, with minor variations. Overt NPs, both subjects and objects, can be introduced into the parse sequence early or late, with the nodes that they serve to decorate either being introduced within a single tree by *Adjunction or being taken to be a linked structure. As in Romance, these different modes of introduction interact with the lexical specifications of the corresponding subject and object markers, introducing locally unfixed nodes so that these can be unified with an already constructed unfixed node, or, in virtue of some bottom restriction, allowing no such update and forcing any co-referring NP to be processed as decorating an independent linked structure. As expected, these different strategies can be used together. As a result, an object expression can be processed by early application of *Adjunction to create an unfixed node, which can then get fixed at the object node once that is introduced by actions of the verb. The subject marker, on the other hand, which provides a type value but only a meta-variable as formula value, will need update from application of Late*Adjunction after the object node is completed; and the decorations of that subject node will then be provided by using a post-verbal subject-marked expression to decorate the introduced unfixed node. An illustration of this is (52), with class 10 subject marking and post-posed agreeing subject, under the assumption that subject markers in Tumbuka have lost their bottom restriction and that the locative term is construed as argument of the predicate:

$$
\begin{array}{llll}
\text { pa-mu-páanda } & z i-k a \text {-dúk-a } & \text { mbúuzi } & \text { [Tumbuka] } \\
\text { 16-3-wall } & \text { SM10-PAST-jump-FV } & 10 . \text { goats } &
\end{array}
$$

'Over the wall jumped goats.' ('The goats jumper over the wall.') (Downing 2006: 62)

The data presented in this section have served to show the parallelism of Romance and Bantu in terms of word-order freedom (through the application of *Adjunction and the building of linked structures), with restrictions on this freedom imposed by the lexical constraints encoded by subject and object markers. However, we have not yet addressed the question of the representation of these subject and object markers, having concentrated merely on their interaction with early and late placed NPs. In the following section, we address this question and argue, taking the conceptual underspecification of Bantu clitics as a starting point, that they are also structurally underspecified, inducing some locally unfixed node which they decorate with a placeholder, with both structural relation and formula value needing to be updated.

\section{Inducing locally unfixed nodes: Otjiherero sub- ject markers}

We argued above that Romance clitics may decorate locally unfixed nodes, the clitic system overall being a reflex of the historic case system of Latin and its constructive use 
in scrambling. We will employ the same notion of locally unfixed nodes for an analysis of subject and object markers in Otjiherero, arguing synchronically with evidence from passive and locative inversion constructions that the Bantu subject-marking system parallels the scrambling-induced actions of Romance. ${ }^{14}$ From this it also follows that in contrast to subject pro-drop in Spanish, where we have analyzed the verbal actions as providing both a subject node and a meta-variable as decoration, we analyze subject 'pro-drop' in Bantu as resulting from the lexical actions of the subject markers, similar to the actions provided by pronominal object clitics in Romance. Since subject markers are obligatory cross-Bantu, this means that overt NP subjects are always taken either to decorate a linked structure with a copy of the term they provide having to be constructed in the primary structure, or an unfixed node, in which case that node will have to unify with the node decorated by the subject marker. The analysis is motivated initially through the parallelism with Romance, and as formal reflex of the observation that Bantu clitics are pronoun-like. However, crucial to the analysis to be given is that the subject marker induces the building of a locally unfixed node which it decorates with a meta-variable as formula value without updating that structural relation. The following steps of the derivation of (53) illustrate the analysis.

$$
\begin{aligned}
& \text { Kàtènáà } \quad w \text {-á-kòtòk-á } \\
& \text { 1a.Katenaa } \\
& \text { 'Katenat-PAST-return-FV returned.' }
\end{aligned}
$$

Parsing Kàtènáà w in (53)

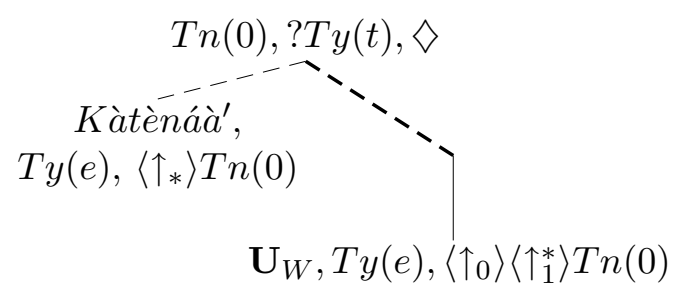

We assume that the subject NP decorates an unfixed node introduced by *Adjunction. We could equally have chosen to introduce an independent linked structure into the emergent overall structure, since both strategies are available. However, as mentioned above, under the locally unfixed node analysis for subject markers, full NP subjects will never be taken to provide the decorations for a fixed node because no fixed node is available if the subject precedes the verb. Following the construction of the unfixed node decorated by the preposed expression, we assume as with the Romance object clitics that it is the subject marker that induces the building of a locally unfixed node, to which it adds a meta-variable decoration. We assume furthermore that the subject marker encodes as formula value a pronominal meta-variable restricted by the associated class information (in this case expressed as a subscripted W), and we leave it to one side how this information is spelled out (see Cann et al. 2005: chapter 7). Note that the two unfixed nodes can unify at this stage; and indeed in this derivation they do so, with the actions induced by the subject marker having initiated the local domain within which the left-peripheral expression will be interpreted. The next step 
is to scan the lexical information from the tense morpheme. We assume that the tense marker not only provides semantic information about the time of the event (an annotation on the root node), but also provides a skeletal predicate frame with subjectand predicate-requiring nodes, reflecting the probable historical origin of many Bantu tense markers as verbs:

\section{Parsing Kàtènáà w-á in (53)}

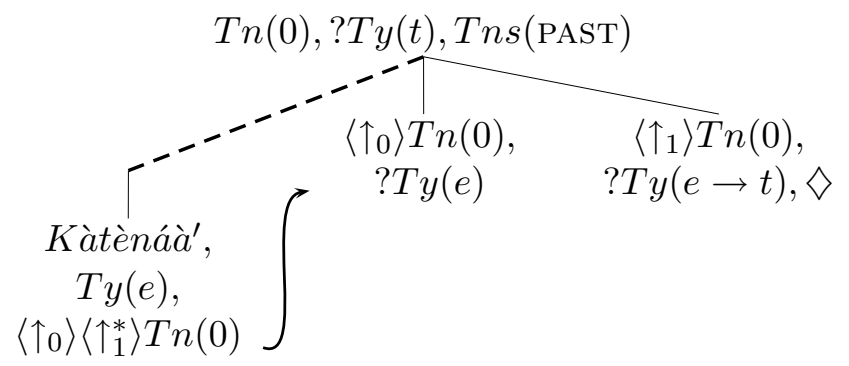

With the new presence of a fixed subject node, the unfixed node-relation could now be fixed by unifying the two nodes, and in this simple case they do so (it is with the passive and locative cases that we shall see, this option is not taken up). ${ }^{15}$ Hence the decoration of the subject is completed at this stage, and the information from the verb then annotates the predicate node as the next step. The final step in the derivation is the parsing of the final vowel, which induces the eventual construction of the predicate, and then all semantic information in the tree is duly compiled up progressively so that a final propositional formula of type $t$ is derived as decoration to the top node, satisfying the overall requirement. While the eventual tree for (53) looks like an ordinary subject-predicate structure, it is important to keep in mind that its derivation involved construction steps at which first one unfixed node and then one locally unfixed node were part of the tree.

One of the reasons for analysing subject markers in Otjiherero as triggering the building of unfixed nodes was to extend what is a parallelism between Romance and Bantu clitics so that it applies also to the Bantu subject clitic (which not all Romance languages display). ${ }^{16}$ We have so far discussed similarities between the two language groups with respect to the different word-order possibilities of full NPs, which we have analysed as resulting from the interplay of linked structures, ${ }^{*}$ Adjunction and different lexical specifications of co-referential pronominal elements. Now we propose that in terms of structural and referential properties of their pronominal elements also, the two language groups are similar in that, in both groups, pronominal elements are typically positioned close to the verb stem because they trigger the building of locally unfixed nodes. However, whereas in Romance, the projection of locally unfixed nodes for a clitic coincides with remnants of a case system, so that locally unfixed nodes can be fixed if enough case information is available, thereby licensing the occurrence of multiple clitics, in Otjiherero, locally unfixed nodes are only fixed if a fixed tree node address is provided independently, either by lexical information from the tense marking, or from the verb. This distinction provides the basis for the constraint in Otjiherero, as in many Bantu languages, that only one object marker can be present 
in the inflected verb form. Moreover, it explains why in many noun-classes in the Bantu languages, there is no difference in morphological marking between subject and object marker: all the marker does is to initiate and decorate a locally unfixed node, with some other expressions providing its decoration, and construal as subject or not is only ensured either by the following tense markers (in the case of the subject), or by the following verb in the case of the object marker. Confirmation of this analysis now comes from passive and locative inversion in Otjiherero, which pose the additional puzzle of precluding object prefix-marking, which this analysis now promises to solve.

\section{$5 \quad$ Passive and locative inversion}

Passives have been one of the earliest constructions to be argued to involve movement in generative grammar, based on the older descriptive observation that the logical object of the verb becomes the grammatical subject in the corresponding passive. Accordingly, most analyses of the passive involve the matching of the function of the relevant NP at two different levels: the logical or semantic level, and the grammatical level. The challenge in Dynamic Syntax for an analysis of the passive is that no level of grammatical function is defined: the trees built in Dynamic Syntax are logical or semantic trees, and thus the eventual tree structure associated with both the active and the passive will be a transitive structure, although in the passive the formula value for the logical subject might be an existentially quantified term ('someone'). However the semantic representation of the logical object will be the same for both active and passive, as it will be associated with an argument node below the predicate node. The question then is how to derive such a transitive structure from the passive form of the verb. In the light of the preceding discussion, a natural hypothesis to explore is associating the passive suffix with a delay in unifying the unfixed node provided by the subject marker with the logical-subject node provided by the tense marker. ${ }^{17}$ Delay in unifying the unfixed node is unproblematic: all rules are constraints so not taking up the option of unification is always a possibility. So the unfixed node, now identified as locally unfixed, can remain unfixed until a point at some later stage in the parse when another putative unification site arises, such as, for example, the logical object node supplied by the lexical information from the verb. Thus, we assume that in a parse of (56) the structural option to unify the locally unfixed node after the introduction of the tense marker which supplied the fixed subject node, is NOT taken up in passives, but rather the pointer is moved directly to the predicate node as in (57):

\begin{tabular}{|c|c|c|}
\hline oír & $y-a ́-t j$ & \\
\hline
\end{tabular}

'The letter was written (by the children).' 


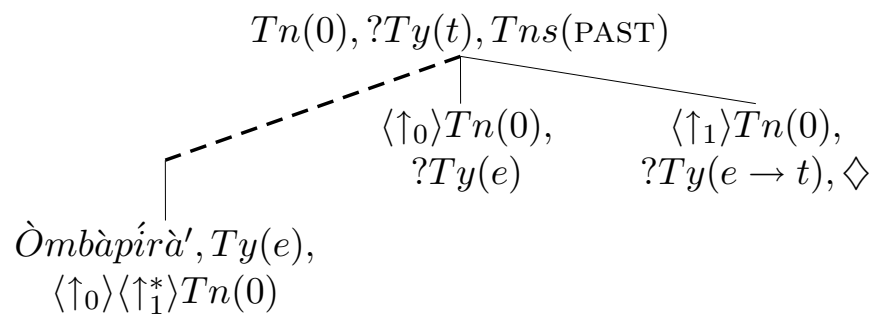

The parsing of the transitive verb stem results in the building of a node for the twoplace predicate, and also for the object argument, this node still requiring a $T y(e)$ expression, all exactly as in the regular transitive cases - indeed at this point in the parse process there is still no indication of any passive form of construal:

\section{Parsing òmbàpírà y-á-tjàng in (56)}

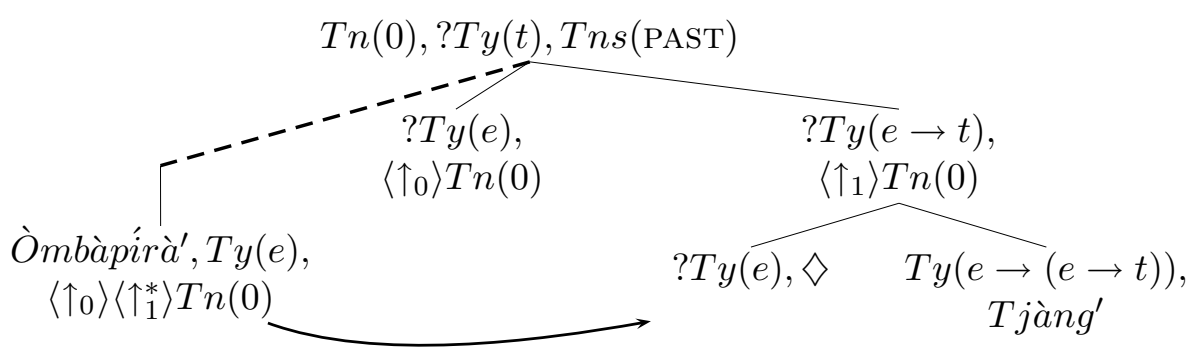

However, since the object node has a requirement for an expression of type $e$, and the locally unfixed node is of $T y(e)$, the locally unfixed node can unify with the object node, in so doing fixing the construal of that front-placed expression as the logical object. As a result, the logical object decorated by òmbàpírà ends up in the correct tree position, all without having to invoke lexical inference or grammatical function changing rules as proposed in LFG (e.g. Mchombo 2005). The interpretation of the logical subject is still outstanding however, and we propose that it is provided as part of the lexical tree-update actions defining the passive marker. That is, the passive suffix is defined as providing an annotation for the subject node, and this forces the compilation of semantic information associated with the predicate in order that the pointer can indeed return to the subject node to provide it with the decorations encoded by the passive suffix. Finally, there is the final vowel $-a$ whose update actions are the indication that the derivation is completed.

It should be noted that on this analysis Bantu 'subject markers' are in fact not logical-subject markers at all, as they can be used, as for example in the passive, to encode logical objects. They are more correctly thought of as mere markers that introduce some local domain whose infra-structure will be built up in what follows. Since the lexically supplied formula specification of the subject is quite weak, it can be updated with information from the context, or by using the agent expression to induce a linked structure (upon a construal of this as background information). Note that what this analysis involves is the assumption that Bantu so-called subject markers are in fact 
clitics with referential and positional freedom comparable to Romance clitics; and, like them, they decorate locally unfixed nodes, with one additional lexical stipulation that the passive morpheme provides an annotation for the logical subject node as a relatively late step in the derivation. In support of this, it is noteworthy that across almost all Bantu languages, the passive morpheme comes last in the series of derivational suffixes, a fact which has been much commented on, but which has not been satisfactorily explained (e.g. Hyman 2003 proposed a 'morphological template' to account for the suffix order). Under this analysis, the final position of the passive reflects its particular function: it does not induce a local action modifying the semantics of the verb, but provides annotations for the logical subject node which the pointer can return to only by compiling up the predicate node, hence providing a last set of steps before the tree as a whole can be completed. In effect, the passive marker thus acts as a closure of the predicate term.

Further support for this analysis comes from the unavailability of object marking in passives in many Bantu languages (Woolford 1995), including Otjiherero. While in passives of transitives, no requisite object exists, and so the absence of object marking is not surprising, the absence of object marking in ditransitives is more puzzling:

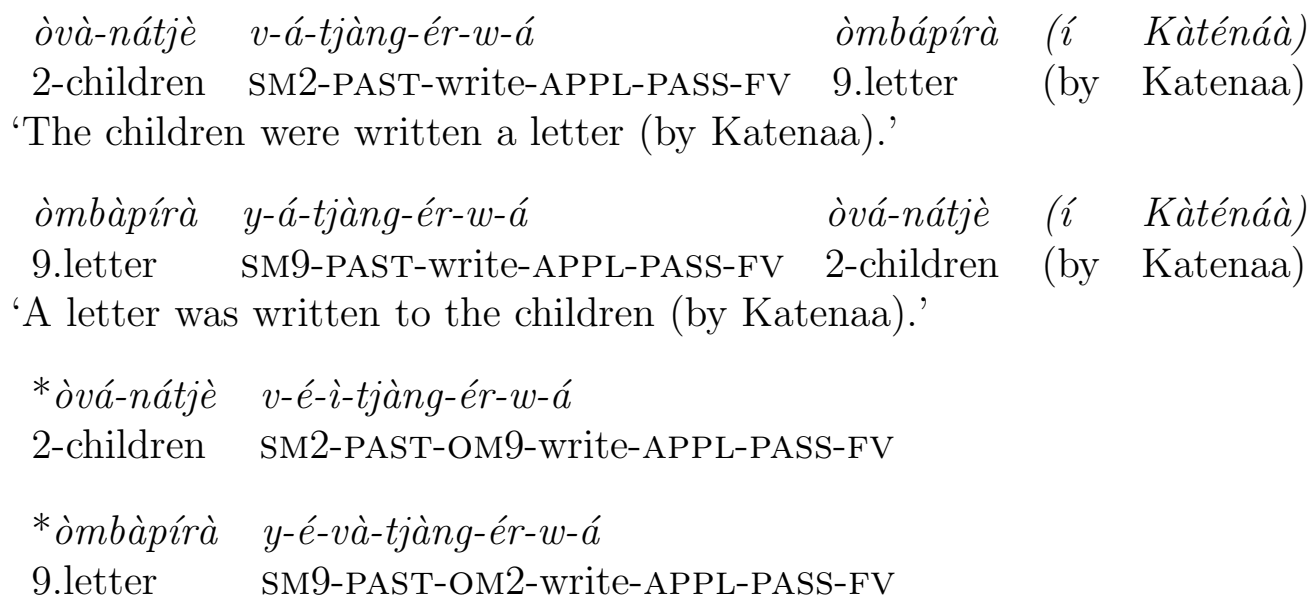

As these data show, Otjiherero allows both the benefactive and the theme object to become subjects and corresponding passives, with the remaining object following the verb. However, neither of the remaining objects may be expressed by an object marker. This fact has sometimes been associated with properties of the relevant objects or the verb, e.g. the unavailability of case marking for object markers in passives. However, as DS does not have a case theory as argument licensing, such an analysis is not readily available in the framework. Instead, the ungrammaticality of object markers in passive structures follows directly from the analysis in terms of building a locally unfixed node to be decorated by what is morphologically the subject. The object marker in active structures is licensed because the locally unfixed node introduced at the outset of the parse is fixed once the tense marker provides a fixed subject node, and so a new locally unfixed node can be built. However, in passives, the initial locally unfixed node is not fixed until the verb has been parsed which provides the fixed object node. But since only one locally unfixed node at a time is normally possible, it follows that no further locally unfixed node, and hence no object marker, can be built before the verb is parsed. 
Once the locally unfixed node has been fixed, it is of course possible to introduce the second objects of the ditransitives after the verb, as the examples above show. This analysis of passive constructions in Otjiherero thus confirms our more general enterprise of uncovering the parallelism between Romance and Bantu, and specifically to describe the variation encountered within the same structural architecture.

Furthermore, our analysis brings out parallels between passive and locative inversion, which are often taken as two distinct problems: passive is seen as a valency changing operation, with distinct morphology and involving some interaction between grammatical function and thematic roles, while locative inversion, on the other hand, has no associated morphology and does not change the valency of the verb. Yet, what is similar about the two constructions is that in both cases, 'subject' agreement is with an NP which is not the logical subject of the verb. Incidentally, both constructions also share de-topicalisation of the logical subject, but we will leave this aside here (see Marten 2006 for more discussion of Otjiherero and Bantu locative inversion):

è-rúngá r-á-hití m-ón-djúwó [Otjiherero]

5-thief SM5-PAST-enter 18-9-house

'The thief entered (into) the house.'

$$
\begin{array}{lll}
\text { m-òn-djúwó } & \text { mw-á-hìtí } & \text { é-rùngà } \\
\text { 18-9-house } & \text { SM18-PAST-enter } & \text { 5-thief }
\end{array}
$$

'Into the house entered the thief.' (or, 'There was a thief entering the house.')

In the locative inversion construction in (64), the locative phrase mòndjúwó precedes the verb and the clitic agrees with it. The logical subject follows the verb, and there is no special morphology associated with the verb. Our analysis of the Otjiherero passive can easily be extended to locative inversion if we assume that the locative is projected as an argument term internal to the predicate. As we have seen above, there is some evidence for this view from object marking, where locative expressions behave like other complements. Similarly, locatives in interaction with applicatives show complement-like behaviour. If we take this as evidence of the argument-hood of the locative term to be constructed, then we can analyse locative inversion exactly like passives with but one minor difference. This is that the interpretation of the logical subject is not provided by any morphological marker, there being no analogue to a stem-final passive marker in locatives: the logical subject thus has to be introduced by parsing of lexical input, which cannot be omitted. This follows because the tense marking, though it provides a subject-predicate skeleton, does not provide any type or formula specification to satisfy the type requirement on the introduced subject node. In the general case this is provided by the subject-marker but in these cases this is unified with the node decorated by the locative, so there is nothing as yet satisfying the requirement on the subject node. Accordingly, the post-posed subject expression in such constructions is obligatory:

$$
\begin{array}{ll}
* \text { *-òn-djúwó } & \text { mw-á-hití } \\
\text { 18-9-house } & \text { SM18-PAST-enter }
\end{array}
$$


Otherwise, the analysis is exactly as in the passive. A parse of the initial locative expression is taken to decorate an unfixed node, and the subject marker provides a locally unfixed node, which duly unifies with the initially constructed unfixed node. The tense specification then provides a skeletal subject predicate structure, but without any decoration of the subject node it introduces other than assigning it a requirement ?Ty $(e)$. By placing the pointer at the predicate node, however, it is the predicate that is then constructed, as in the passive by the parsing of the verb stem. There is no object marker, as we would now expect, as there remains an outstanding locally unfixed node in the construction waiting to be resolved. This can however unify with the locative, on the assumption that these can be taken as arguments of the predicate. This then completes that predicate, almost leading to a complete propositional formula. However, the subject node still has its type requirement outstanding as the tense marker does not project any pronominal-like meta-variable. Hence, having compiled up a predicate interpretation, the pointer has to return to the subject node, at which stage the subsequent 'postposed' subject expression can duly decorate this node as one of the very last steps in the construction process. The main difference between our analysis of the passive and locative inversion is that the passive marker provides the annotation for the subject, while in locative inversion constructions, the subject decoration is provided only as a very late step in the construction process. As is often noted, this structure is characteristically associated with a focus construal of the subject, and we would take this to be a consequence of its highly marked late placement, indicating that everything is in some sense part of the context which it updates. Structurally however, both constructions follow a similar strategy. Both involve the construction of a locally unfixed node at the outset of the parse, which is only unified at the object node once this has been introduced by the verb. Thus, like in the passive, no object markers are possible in locative inversion as long as the verb has not been parsed:

$$
\begin{array}{ll}
{ }^{*} m \text {-on-djuwo } & \text { mw-a-ri-hiti } \\
\text { 18-9-house } & \text { sM18-PAST-OM5-enter }
\end{array}
$$

The reason for this is the same as for the passive, namely that no locally unfixed node can be built as long there is another locally unfixed node present. Since the locally unfixed node with the locative clitic is unified in object position, the post-verbal subject can be expressed by a clitic:

$$
\begin{aligned}
& \text { m-òn-djúwó } \quad \text { mw-á-hití-rò } \\
& \text { 18-9-house SM18-PAST-enter-om5 } \\
& \text { 'He/she entered the house.' }
\end{aligned}
$$

It is sometimes claimed that a crucial characteristic of locative inversion is that it is restricted to a certain set of predicates, characterized by their thematic roles, for example unaccusatives in Chichewa (Bresnan and Kanerva 1989). Since Dynamic Syntax does not have any notion of 'thematic role', this appears to be problematic for our analysis. However, whatever the situation in Chichewa may be, as it turns out, in Otjiherero no such restriction exists (cf. Marten 2006). In (68), the transitive predicate tjánga 'write' is used in a locative inversion construction. It is marked by 
an applicative which in this case introduces the locative argument, further buttressing our analysis of construing the locative within the predicate.

$$
\begin{array}{llll}
p \text {-òn-djúwó } & \text { pé-tjáng-èr-à } & \text { ová-nátjè } & \text { òmbàpírà } \\
\text { 16-9-house } & \text { SM16.HAB-write-APPL-FV } & \text { 2-children } & \text { 9.letter } \\
\text { 'At the house write children a letter.' } & &
\end{array}
$$

As in our analysis of the Otjiherero passive, we have shown that locative inversion can be analysed by assuming that initial clitics in Otjiherero are taken to induce a locally unfixed node which can be unified either with the subject node or, as in passives and locative inversion, with the object node. The analysis brings out both the similarities of the constructions, in particular the fact that the verb-initial clitic agrees with an object NP, and the differences, in particular that in the passive the interpretation of the subject results from lexical information from the passive marker, while in locative inversion, the logical subject is found in immediate post-verbal position.

\section{Reflections and directions for the future}

In this paper, we have taken relatively familiar data from Romance and summarised the basis for a typology of left and right periphery effects, using the Dynamic Syntax notions of LINK and *Adjunction, in conjunction with restrictions encoded in the lexical specifications of different clitics, to derive different word-order effects. After illustrating the analysis with respect to Spanish, we extended it to Bantu, in particular Herero, and showed how word-order variation in Bantu can be captured with the very same strategies introduced for Romance, deriving similar effects on the right and left periphery, through similar interaction between lexically encoded restrictions on the interpretation of pronominal elements and the processes of update involved in the construction of unfixed nodes and linked structures. While this gave an account of word-order variation found in the two language families, for the analysis of clitics (in Romance) and agreement markers (in Bantu), we introduced in addition the notion of local underspecification, a mechanism defined to reflect incremental processing in very free constituent order systems. While in Romance we have analysed the construction of locally unfixed nodes for clitics as remnant reflexes of the case system of Proto-Romance/Latin as it applied in licensing scrambling effects, in Bantu we have simply assumed that the projection of locally unfixed nodes is part of being a Bantu clitic. By applying this analysis to active, passive and locative inversion construction in Otjiherero, we have shown how a number of structural properties of Otjiherero are predicted by the analysis: the availability of only one object marker per verb, unrestricted as to case or thematic role; the absence of pre-verbal object markers in passive and locative inversion; the final position of the passive morpheme in the string of derivational suffixes; the obligatory post-verbal position of the logical subject in locative inversion, and the association with presentational focus of locative inversion constructions. After having shown the empirical advantages of our analysis, we turn in this final section briefly to some conceptual implications. 
In Bantu linguistics, it is usually assumed that subject and object marker are part of the verbal morphology. Our analysis departs from this assumption, by proposing an analysis which essentially accords these markers much more structural freedom. We hope with this to have opened a more general discussion about agreement in Bantu, which might shed light not only on passives and locative inversion, but also, for example, on subject-object reversal constructions (to which the present analysis could in principle be extended), topic agreement, and default expletive agreement markers found in many Bantu languages. Based on the analysis proposed here, the question of multiple object markers can be more precisely addressed, where it is worth exploring whether multiple object markers may be analysed as complex locally unfixed nodes, or as a mixture of fixed and unfixed nodes. In this connection, there is also the possibility that these reflect some earlier scrambling stage more directly, and involve the construction of complexes of argument nodes, parallelling the Romance clitics and their mirroring of earlier Latin scrambling. By providing a new way of thinking about Bantu subject and object agreement marker, we hope to have opened avenues for thinking about a number of issues in Bantu grammar from a different perspective.

With regard to the DS approach, the analyses presented here have addressed two main issues. First, a key element in our analysis is the use of underspecification of different kinds. Underspecification of content is relevant for the analysis of pronominal elements which encode an underspecified formula value in need of contextual enrichment. Structural underspecification is at the core of our use of *Adjunction which allows the introduction of some information at a node whose position in the tree is not fully specified at the time it is introduced, and thus needs to be fixed at a later stage. These two different forms of underspecification are combined in the analysis of Romance clitics and Bantu agreement markers as encoding both underspecified pronominal content and the construction of locally unfixed nodes. By comparing Spanish as illustrative of Romance and Herero as illustrative of Bantu, we have shown how these different forms of underspecification play a role in both language families, while being encoded and restricted in different idiosyncratic ways to yield a range of variation within an overall principles analysis. Secondly, the discussion presented addresses the problem of the representation of thematic roles and grammatical functions within the theory. Without making use of thematic roles of grammatical functions as primitives of the theory, both passive and locative inversion structures seem to pose a problem for Dynamic Syntax, since these notions are often thought to be essential for a successful analysis. However, we have shown that by employing locally unfixed nodes, we derive the appropriate semantic representations in a left-to-right fashion, without invocation of these concepts. It remains to be seen whether this line of thinking can be extended to the analysis of other constructions often associated with thematic roles and grammatical functions in other languages.

As a final remark, we address the question of the more general significance to be drawn from our proposed account of the "surface subject" in Bantu. The concept of locally unfixed node, central to the Bantu analysis, was originally developed for scrambling effects (Cann et al. 2005), and applied to model behaviour of case-marked Romance clitics (Kempson and Cann 2007). However, as we have shown, the mechanisms needed for such an account indubitably apply to the case of subject, as we have 
shown, enabling one to provide a new basis for grappling with the otherwise puzzling concept of syntactic subject. Though the behaviour of locatives in Otjiherero is idiosyncratic to the Bantu languages, what it suggests more generally is that the concept of syntactic subject may be heterogeneous, a genuine epiphenomenon. As both our Bantu and Romance analyses show, subjects can be introduced into the parse through a variety of means, as decorating fixed, unfixed or linked nodes, and as being coreferential with pronouns, clitics or agreement markers. From a parsing perspective, with alternate strategies available at any point, and with different calcifications over time consolidating to give rise to subtly different patterns, what is common to all such subject marking is a parsing identification of a distinct emergent local predicate-argument structure. This new light on the reducibility of the concept of syntactic subject to a number of different forms of tree growth update, integral as it is to a procedural perspective, opens up new ways of looking at a well-known but mysterious phenomenon. Indeed, the general dynamics of the parsing perspective promises to provide new solutions to the family of puzzles associated with the interaction of structural processes in natural language and the anaphoric devices such as clitics and agreement markers that languages make available. 


\section{Notes}

${ }^{1}$ We are grateful to Jekura Kavari, Nancy Kula, Clara Simango, Nhlanhla Thwala and audiences in Groningen, Leiden, Oxford and Leeds for helpful comments on parts of this paper, as well as to Helsinki University Library for granting access to their Swahili corpus. Parts of the research reported in this paper have received financial support from the AHRC (B/RG/AN8675/APN16312) which is hereby gratefully acknowledged.

${ }^{2}$ The term clitic doubling is here used non-technically to mean use of an NP with co-construed clitic for both right- and left-peripheral NPs. We use the following abbreviations in the glosses: $\mathrm{A}=$ 'personal a', $\mathrm{ACC}=$ accusative, $\mathrm{APPL}=$ applicative, $\mathrm{CL}=$ clitic, $\mathrm{FUT}=$ future, $\mathrm{FV}=$ final vowel, $\mathrm{HAB}=$ habitual, $\mathrm{NOM}=$ nominative, $\mathrm{OM}$ $=$ object marker, PASS $=$ passive, $\mathrm{PL}=$ plural, $\mathrm{SG}=$ singular, $\mathrm{SM}=$ subject marker, $1,2,3,=$ noun class number. We are grateful to Jekura Kavari, Clara Simango and Nhlanhla Thwala for providing the Otjiherero, Nsenga and siSwati examples. Chichewa examples are from Bresnan and Mchombo (1987).

${ }^{3}$ Potential complications for this account arise with se, which can co-occur with both $m e$ and te and may give rise to clitic clusters (Cuervo 2002, Heap 2005). But there is reason to think that in all such cases $s e$ is an ethical dative use, for which there is considerable evidence of its requiring an independent adjunct analysis (Cuervo 2002).

${ }^{4}$ It is not possible in the space provided to give a full introduction to DS, nor to provide full justification for the Romance analyses we discuss. See Cann et al. 2005, Kempson et al. 2006, Kempson and Cann 2007, Bouzouita 2007, Bouzouita in preparation, Bouzouita and Kempson 2006, which present more detail.

${ }^{5}$ By convention, nodes decorated by functor types are on the right, nodes decorated by argument types are on the left. In all tree displays, we give only such tree decorations as are needed to demonstrate the point in question.

${ }^{6}$ In any partial tree, there is one node indicated by a pointer, $\diamond$, as the node under development. In this framework all noun phrase construals are taken to be of type $e$, matching arbitrary names manipulated in natural-deduction proofs. Accordingly, the terms onto which words map are lambda terms within the epsilon calculus (the epsilon calculus provides the formal study of arbitrary names - see Meyer-Viol 1995). In general, we ignore the internal structure to be assigned to such type $e$ names.

${ }^{7}$ As Zagona (2002: 27) points out, the acceptability judgments for the VSO order in finite declaratives vary from speaker to speaker, some reporting it as archaic.

${ }^{8}$ Details of individual terms are omitted, including the internal structure of the composite term projected from familias de pocos medios, diagrammatically represented as projecting the predicate $F P M^{\prime}$. 
${ }^{9}$ Formally, this is defined using the Kleene star operation defined on the daughtermother relation: $\left\langle\uparrow_{*}\right\rangle \operatorname{Tn}(a)$ is a node dominated by some node $\operatorname{Tn}(a)$, where $\operatorname{Tn}(a)$ is along some arbitrary sequence of mother relations from the current node to $T n(a)$. Adding the requirement ? $\exists x . T n(x)$ as an additional decoration on that node imposes the requirement that in all successful completions of the tree, this underspecified characterisation is replaced by a fixed tree relation. Cf. Kaplan and Zaenen (1989) for use of the Kleene star in defining the related concept of 'functional uncertainty' in LFG.

${ }^{10}$ Instead of, or in addition to, case specifications there may be pragmatic and prosodic clues, which are, however, likely to be less secure.

${ }^{11}$ We leave on one side whether enclitic forms are directly lexically specified or induced via Local*Adjunction.

${ }^{12}$ In Mexican Spanish the sequence se los can be associated with a construal in which the dative se picks out a set of individuals, while the accusative los picks out a single entity, although bearing a plural marker. So (1) is multiply ambiguous according to its interpretation as: 'them to him/her', 'it to them', 'them to them':

$$
\begin{array}{llll}
S e & \text { los } & d i . & \text { [Mexican Spanish] } \\
\text { CL } & \text { CL.PL } & \text { gave.1SG } &
\end{array}
$$

'I gave it to them.' or 'I gave them to him/her.' or 'I gave them to them.'

${ }^{13}$ Multiple object markers, under this view, are only possible if they are taken to induce a complex of nodes built from a single intermediate propositional node, itself unfixed (a characteristic of scrambling languages: Kiaer 2007), or if the node each one induces is fixed immediately, involving a pragmatic notion of constructive case (McCormack 2008). However, we will focus on one object marker languages, more specifically on Otjiherero in the following sections, and will leave multiple object markers to one side for the present.

${ }^{14}$ The notion of locally unfixed nodes is independent of the notion of case, and so we are not proposing that Bantu languages have grammatical case, since it is widely known that they do not. On the other hand, there are in fact isolated instances of morphological differences between subject and object markers, e.g. Proto-Bantu class 1 (3rd sing) subject $*^{*} a ́$ - vs object ${ }^{*} m \grave{u}$, 1 st pl. subject ${ }^{*} t \grave{u}$ vs. object $* t u ́$ (Meeussen 1967), so the point might be worth revisiting.

${ }^{15}$ By definition of the Kleene star operator, the set of relations denoted can be empty, in this case, the possible sequence of functor relations being null, allowing enrichment as the subject relation.

${ }^{16}$ In French, there is clear evidence that the pronoun does not decorate an unfixed node, as the referentiality restriction on subject clitic doubling remains completely undisturbed. In the Northern Italian dialects however, an account of subject clitic doubling might arguably follow lines similar to those developed here (cf. Poletto 2000). 
${ }^{17}$ An alternative analysis in the system would be to invoke steps of inference between different, albeit related concepts and their associated propositional structures. For further discussion of analyses of passives in DS, see Cann and Wu (2006). 


\section{References}

Anagnostopoulou, E., van Riemsdijk, H. and Zwarts, F. (eds). 1997. Materials on Left Dislocation. Amsterdam: John Benjamins.

Blackburn, P. and Meyer-Viol, W. 1994. Linguistics, logic and finite trees. Bulletin of the Interest Group for Pure and Applied Logic 2: 3-29.

Bouzouita, M. in preparation. The Diachronic Development of Spanish Clitic Placement. PhD Dissertation, King's College London.

Bouzouita, M. 2007. Processing factors in syntactic variation and change: Clitics in Medieval and Renaissance Spanish. In Historical Linguistics 2005, J. Salmons and S. Dubenion-Smith (eds), 51-71. Amsterdam: John Benjamins.

Bouzouita, M. and Kempson, R. 2006. Clitic placement in Old and Modern Spanish: a Dynamic Account". In Competing Models of Linguistic Change, O. Nedergaard Thomsen (ed.), 253-268. Amsterdam: John Benjamins.

Bresnan, J. and Kanerva, J. 1989. Locative inversion in Chichewa. Linguistic Inquiry 20: $1-50$.

Bresnan, J. and Mchombo, S.A. 1987. Topic, pronoun, and agreement in Chichewa. Language 63: 741-782.

Cann, R. and Wu, Y. 2006. The dynamic syntax of Chinese passive constructions. Ms., University of Edinburgh and University of Hong Kong.

Cann, R., Kempson, R. and Marten L. 2005. The Dynamics of Language. Oxford: Elsevier.

Cardinaletti, A. forthcoming. On clitic clusters. In this volume.

Cocchi, G. 2001. Free clitics and bound affixes: Towards a unitary analysis. In Clitics in Phonology, Morphology and Syntax, B. Gerlach and J. Grijzenhout (eds), 85-119. Amsterdam: John Benjamins.

de Cat, C. 2007. Dislocation without movement. Natural Language and Linguistic Theory 25: 485-534.

Downing, L. 2006. The prosody and syntax of focus in Chitumbuka. In Papers in Bantu Grammar and Description [ZAS Papers in Linguistics 43], L. Downing, L. Marten and S. Zerbian (eds), 55-79. Berlin: ZAS.

Franco, J. 2000. Agreement as a continuum. In Clitic Phenomena in European Languages, F. Beukema and M. den Dikken (eds), 147-188. Amsterdam: John Benjamins. Hyman, L.M. 2003. Suffix ordering in Bantu: a morphocentric approach. In Yearbook of Morphology 2002, G. Booij and J. van Marle (eds), 245-281. Berlin: Mouton.

Kaplan, R. and Zaenen, A. 1989. Long-distance dependencies, constituent structure, and functional uncertainty. In Alternative Conceptions of Phrase Structure, M. Baltin and A. Kroch (eds), 17-42. Chicago University Press.

Kempson, R. and Cann, R. 2007. Dynamic Syntax and dialogue modelling: preliminaries for a dialogue-driven account of syntactic change. In Historical Linguistics 2005, J. Salmons and S. Dubenion-Smith (eds), 73-101. Amsterdam: John Benjamins.

Kempson, R., Cann, R. and Kiaer, J. 2006. Topic, focus and the structural dynamics of language. In The Architecture of Focus, S. Winkler and V. Molnár (eds). Berlin, New York: Mouton de Gruyter.

Kempson, R., Kiaer, J. and Cann R. 2007. Periphery effects and the dynamics of tree growth. In Dislocated Elements in Discourse, B. Shaer, W. Frey and C. Maienborn 
(eds), 141-170. London: Routledge.

Kempson, R., Meyer-Viol M. and Gabbay D. 2001. Dynamic Syntax. Oxford: Blackwell.

Kiaer, J. 2007. Processing and Interfaces in Syntactic Theory: the case of Korean. PhD dissertation, King's College London.

Marten, L. 2006. Locative inversion in Otjiherero: More on morpho-syntactic variation in Bantu. In Papers in Bantu Grammar and Description [ZAS Papers in Linguistics 43], L. Downing, L. Marten and S. Zerbian (eds), 97-122. Berlin: ZAS.

Marten, L. 2007. Focus strategies and the incremental development of semantic representations: evidence from Bantu. In Focus Strategies in African Languages, E. O. Aboh, K. Hartmann and M. Zimmermann (eds), 113-135. Berlin/New York: Mouton de Gruyter.

Marten, L. and Kempson, R. 2002. Pronouns, agreement, and the dynamic construction of verb phrase interpretation: A Dynamic Syntax approach to Bantu clause structure. Linguistic Analysis 32: 471-504.

Mchombo, S. 2005. The Syntax of Chichewa. Cambridge: Cambridge University Press. McCormack, A. 2008. Object marking in Tswana: A Dynamic Syntax analysis. PhD dissertation, School of Oriental and African Studies.

Meeussen, A. E. 1967. Bantu grammatical reconstruction. Africana Linguistica 3: 80-122.

Meyer-Viol, W. 1995. Instantial Logic: An investigation into reasoning with instances. $\mathrm{PhD}$ dissertation, University of Utrecht.

Monachesi, P. 2005. The Verbal Complex in Romance, Oxford: Oxford University Press.

Mvungi, M. n.d. Lwidiko. Dar es Salaam: Tanzania Publishing House.

Nordlinger, R. 1998. Constructive Case: Evidence from Australian languages. Stanford: CSLI.

Poletto, C. 2000. The Higher Functional Field: Evidence from northern Italian dialects. Oxford: Oxford University Press.

Rivero, M-L. forthcoming. Oblique subjects and person restrictions in Spanish: a morphological approach. In Agreement Restrictions, R. D'Alessandro, S. Fischer and G. Hrafnbjargarson (eds). Berlin: de Gruyter.

Rizzi, L. 1997, The fine structure of the left periphery. In Elements of Grammar, L. Haegeman (ed.), 289-330. Dordrecht: Kluwer.

Sperber, D. and Wilson, D. 1995. Relevance: Communication and Cognition. Oxford: Blackwell.

Woolford, E. 1995. Why passive can block object marking. In Theoretical Approaches to African Languages, A. Akinlabi (ed.), 199-215. Trenton, NJ: Africa World Press.

Wu, Y., 2005. The Dynamics of Left and Right Dislocation on Chinese. PhD dissertation, University of Edinburgh.

Zagona, K. 2002. The Syntax of Spanish. Cambridge: Cambridge University Press.

Zubizarreta, M.L. 2001. The constraint on preverbal subjects in Romance interrogatives: a Minimality effect. In On Romance Inversion, A. Hulke and J-Y Pollock (eds), 183-204. Oxford: Oxford University Press. 